\title{
Review Article \\ Solid Tumor-Targeting Theranostic Polymer Nanoparticle in Nuclear Medicinal Fields
}

\author{
Akira Makino $^{1,2}$ and Shunsaku Kimura ${ }^{3}$ \\ ${ }^{1}$ Biomedical Imaging Research Center (BIRC), University of Fukui, Fukui 910-1193, Japan \\ ${ }^{2}$ Research and Education Program for Life Science, University of Fukui, Fukui 910-1193, Japan \\ ${ }^{3}$ Department of Material Chemistry, Graduate School of Engineering, Kyoto University, Kyoto 615-8510, Japan
}

Correspondence should be addressed to Akira Makino; amakino@u-fukui.ac.jp

Received 27 June 2014; Revised 8 August 2014; Accepted 11 August 2014; Published 14 October 2014

Academic Editor: Masashi Ueda

Copyright (C) 2014 A. Makino and S. Kimura. This is an open access article distributed under the Creative Commons Attribution License, which permits unrestricted use, distribution, and reproduction in any medium, provided the original work is properly cited.

\begin{abstract}
Polymer nanoparticles can be prepared by self-assembling of amphiphilic polymers, and various types of molecular assemblies have been reported. In particular, in medicinal fields, utilization of these polymer nanoparticles as carriers for drug delivery system (DDS) has been actively tried, and some nanoparticulate drugs are currently under preclinical evaluations. A radionuclide is an unstable nucleus and decays with emission of radioactive rays, which can be utilized as a tracer in the diagnostic imaging systems of PET and SPECT and also in therapeutic purposes. Since polymer nanoparticles can encapsulate most of diagnostic and therapeutic agents with a proper design of amphiphilic polymers, they should be effective DDS carriers of radionuclides in the nuclear medicinal field. Indeed, nanoparticles have been recently attracting much attention as common platform carriers for diagnostic and therapeutic drugs and contribute to the development of nanotheranostics. In this paper, recent developments of solid tumor-targeting polymer nanoparticles in nuclear medicinal fields are reviewed.
\end{abstract}

\section{Introduction}

Nanoparticles have been actively examined as carriers for drug delivery system (DDS), which make it possible to improve therapeutic efficacy and to suppress side effects of the parent drug [1-5]. Among various types of nanoordered carriers including inorganic and lipid particles, polymeric micelles and vesicles, which are prepared from selfassembling process of amphiphilic polymers, can encapsulate in general hydrophobic and hydrophilic compounds in the hydrophobic core and inner aqueous cavity regions, respectively [6-10]. Further, not only surface modification but also functionalization of these nanoparticles is possible with ease by using suitably designed amphiphilic polymers. Therefore, polymeric nanoparticles have received much attention as the DDS carriers.

Additionally, nanoparticles are originally accumulated at the region where cells are rapidly proliferating, because leakage of nanoparticles can occur through the holes on immature blood vessels. Combined with the effect of undeveloped lymph system at tumor region, nanoparticles are retained there, leading to the passive accumulation. This phenomenon is called the enhanced permeability and retention (EPR) effect and is one of the most frequently utilized methodologies of nanoparticles for DDS [11-13]. On the basis of these reasons, polymeric nanoparticle is a suitable carrier for solid tumors-targeting DDS $[8,14]$. In fact, various tumortargeting DDS carriers have been developed, and some polymeric nanoparticles encapsulating antitumor drugs are currently under clinical trials [15].

Recently, polymeric nanoparticles are also applied as carriers for contrast agents in the field of in vivo imaging [1618]. Among various modalities such as near-infrared fluorescence (NIRF) imaging, magnetic resonance imaging (MRI), positron emission tomography (PET), and single photon emission computed tomography (SPECT) systems, the in vivo near-infrared fluorescence (NIRF) imaging system has shown amazing progresses. This is because handling of the NIRF compounds is relatively easy and its biodistribution can be directly visualized. However, penetration depth of 
TABLE 1: Representative radionuclides used for imaging and radiotherapy.

\begin{tabular}{lccc}
\hline Radionuclide & Emission type & Half-life & \\
${ }^{11} \mathrm{C}$ & $\beta^{+}(99.8 \%), \gamma(0.2 \%)$ & $20.39 \mathrm{~min}$ & Usage $^{1}$ \\
${ }^{13} \mathrm{~N}$ & $\beta^{+}(99.8 \%), \gamma(0.2 \%)$ & $9.965 \mathrm{~min}$ & $\mathrm{I}$ \\
${ }^{15} \mathrm{O}$ & $\beta^{+}(99.9 \%), \gamma(0.1 \%)$ & $2.037 \mathrm{~min}$ & $\mathrm{I}$ \\
${ }^{18} \mathrm{~F}$ & $\beta^{+}(96.7 \%), \gamma(3.3 \%)$ & $109.8 \mathrm{~min}$ & $\mathrm{I}$ \\
${ }^{32} \mathrm{P}$ & $\beta^{-}(100 \%)$ & 14.24 day & $\mathrm{I}$ \\
${ }^{64} \mathrm{Cu}$ & $\beta^{+}(17.4 \%), \gamma(43.6 \%)$, & $12.70 \mathrm{~h}$ & \\
${ }^{89} \mathrm{Sr}$ & $\beta^{-}(39.0 \%)$ & 50.53 day & $\mathrm{T}$ \\
${ }^{90} \mathrm{Y}$ & $\beta^{-}(100 \%)$ & $64.00 \mathrm{~h}$ & $\mathrm{~T}$ \\
${ }^{99 \mathrm{~m}} \mathrm{Tc}$ & $\beta^{-}(100 \%)$ & $6.015 \mathrm{~h}$ & $\mathrm{~T}$ \\
${ }^{111} \mathrm{In}$ & $\gamma(>99.9 \%)$ & 2.805 day & $13.22 \mathrm{~h}$ \\
${ }^{123} \mathrm{I}$ & $\gamma(100 \%)$ & 59.40 day \\
${ }^{125} \mathrm{I}$ & $\gamma(100 \%)$ & 8.021 day & $\mathrm{T} / \mathrm{I}$ \\
${ }^{131} \mathrm{I}$ & $\gamma(100 \%)$ & 3.718 day \\
${ }^{186} \mathrm{Re}$ & $\beta^{-}$ & $17.00 \mathrm{~h}$ & $\mathrm{I} / \mathrm{I}$ \\
${ }^{188} \mathrm{Re}$ & $\beta^{-}, \gamma$ & $7.214 \mathrm{~h}$ & $\mathrm{~T} / \mathrm{I}$ \\
${ }^{211} \mathrm{At}$ & $\beta^{-}, \gamma$ & 2.14 min & $\mathrm{T} / \mathrm{I}$ \\
${ }^{213} \mathrm{Bi}$ & $\alpha$ & 10.0 day & $\mathrm{T} / \mathrm{I}$ \\
${ }^{225} \mathrm{Ac}$ & $\alpha$ & $\mathrm{T}$ & $\mathrm{T}$ \\
\hline
\end{tabular}

${ }^{1}$ Radionuclide usage for imaging and therapy are abbreviated as "I" and "T," respectively.

near-infrared light in tissue is limited to a few centimeters [19]. Therefore, the NIRF imaging system is suitable for in vivo experiments using small animals, but its applicative area in human clinical uses is limited to near the surface where fluorescent signal can be detectable. On the other hand, in general, sensitivity of nuclear imaging is high. Further, quantitative analyses are available by using PET images. When it comes to the quantitative performance, SPECT is less competitive than PET but has been improved by recent mechanical developments [20]. Positron emitters such as ${ }^{11} \mathrm{C}$, ${ }^{13} \mathrm{~N},{ }^{15} \mathrm{O},{ }^{18} \mathrm{~F}$, and ${ }^{64} \mathrm{Cu}$ are used for PET imaging as signal sources, and $\gamma$-ray emitters such as ${ }^{99 \mathrm{~m}} \mathrm{Tc},{ }^{111} \mathrm{In}$, and ${ }^{123} \mathrm{I}$ are for SPECT imaging (Table 1). For preparation of nanoparticle type probes for nuclear imaging techniques, strategies on how to encapsulate these radioisotopes into nanoparticles are important. There are considerable approaches for the encapsulation, which can be classified into three categories: (1) hydrophobized radionuclides are encapsulated into the hydrophobic core region of polymeric micelle, (2) radionuclide solution is encapsulated into the inner cavity of vesicular assemblies, and (3) metal radionuclides such as ${ }^{64} \mathrm{Cu}$ and ${ }^{99 \mathrm{~m}}$ Tc can be attached to the nanoparticles as chelates by modifying constituent amphiphilic polymers with appropriate chelators. About the inner radiation therapy, $\beta^{-}$ray emitters, such as ${ }^{90} \mathrm{Y}$ and ${ }^{131} \mathrm{I}$, are generally used. In addition, attempts to utilize radionuclides emitting $\alpha$-ray $\left({ }^{211} \mathrm{At},{ }^{213} \mathrm{Bi}\right)$ and auger electron $\left({ }^{99 \mathrm{~m}} \mathrm{Tc},{ }^{111} \mathrm{In}\right.$, and $\left.{ }^{125} \mathrm{I}\right)$ are also performed (Table 1) [21-25]. Any radionuclides labeled nanoparticle can be prepared by selecting appropriate methods for encapsulation as written above.
In this review, recent research developments on solid tumor-targeting DDS using polymer nanoparticle carriers in nuclear medicinal fields are summarized.

\section{Polymeric Micelles}

\subsection{Importance of Surface Modification with Poly(ethylene glycol) (PEG)}

2.1.1. Poly(methyl acrylate)-b-poly(acrylic acid). One of the initial trials to utilize polymeric micelle as a carrier for PET tracer agent was performed in 2005 by Rossin et al. [26]. Polymeric micelle was prepared from amphiphilic poly (methyl acrylate)- $b$-poly(acrylic acid) $\left(\mathrm{PMA}_{164}-b\right.$-PAA $\left.{ }_{93}\right)$, which was synthesized via sequential atom transfer radical polymerization (ATRP) [27]. As illustrated in Figure 1, PMA- $b$-PAA in the micelle was cross-linked between the carboxyl acid group of PAA and the amine functionalities of $2,2^{\prime}$-(ethylenedioxy)diethylamine poly(acrylic acid) to form shell cross-linked (SCK) nanoparticles. Folate receptor (FR) is well-known molecular target for tumor therapies [28], and therefore, folate-poly(ethylene glycol)-amine was conjugated to the surface of the micelle. Further, 1,4,8,11tetra-azacyclotetradecane- $N^{\prime}, N^{\prime \prime}, N^{\prime \prime \prime}, N^{\prime \prime \prime \prime}$-tetra-acetic acid (TETA) was also modified to the micelle surface for ${ }^{64} \mathrm{Cu}$ chelate formation.

Using tumor transplanted mice, biodistribution of the micelle was examined by organ harvesting method. The micelle was recognized by reticuloendothelial system (RES), which is self-defense system of living organisms, and its 


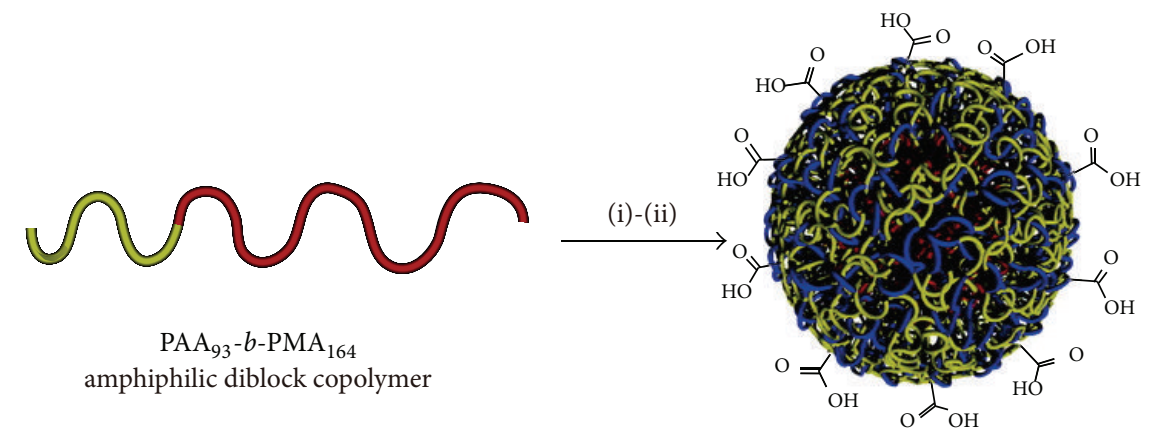

Shell cross-linked nanoparticles (SCKs)

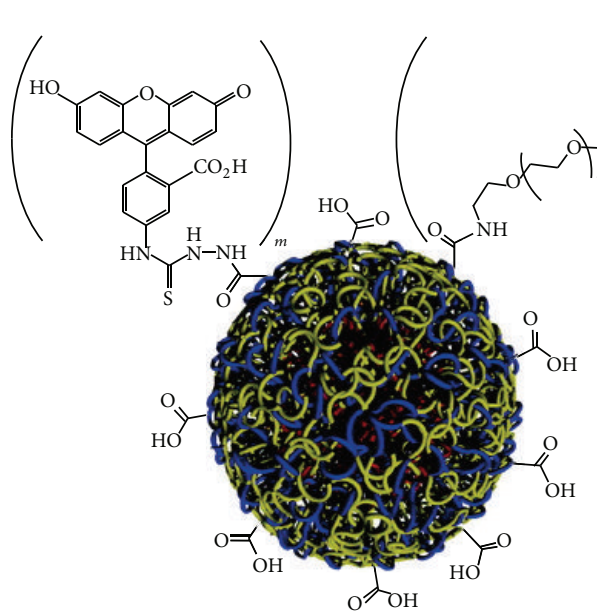

FTSC labeled folate functionalized SCKs

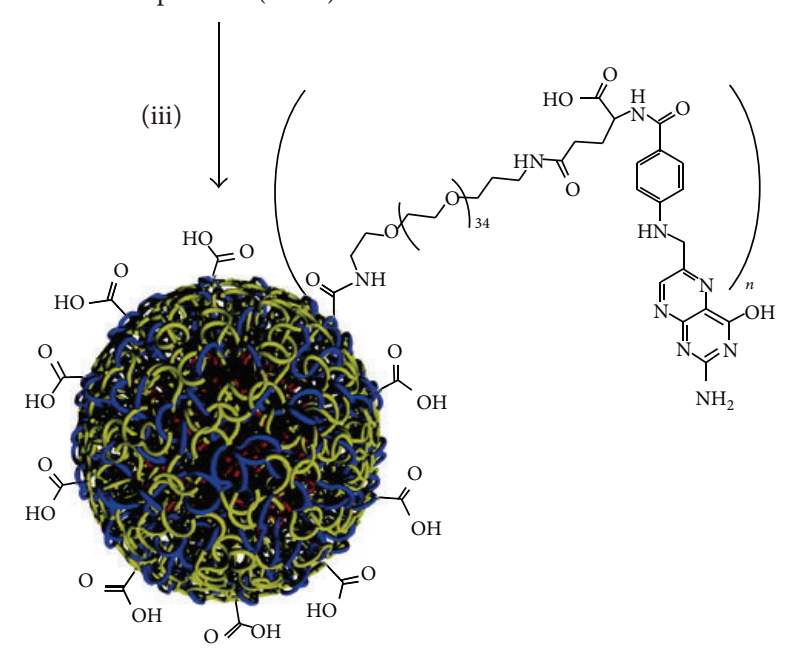

Folate functionalized SCKs

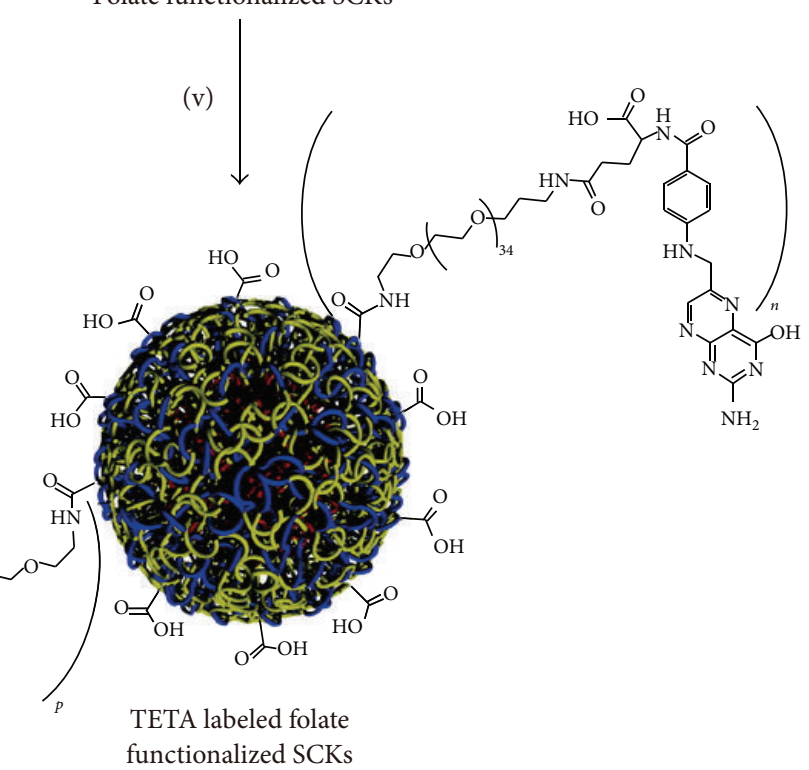

FIgure 1: Polymeric micelle prepared from PMA- $b$-PAA. This research was originally published in JNM. R. Rossin, D. P. J. Pan, K. Qi, J. L. Turner, X. K. Sun, K. L. Wooley, and M. J. Welch. "Cu-64-labeled folate-conjugated shell cross-linked nanoparticles for tumor imaging and radiotherapy: Synthesis, radiolabeling, and biologic evaluation." J. Nucl. Med. 2005, 46, 1210-1218. The Society of Nuclear Medicine and Molecular Imaging, Inc ( ). 


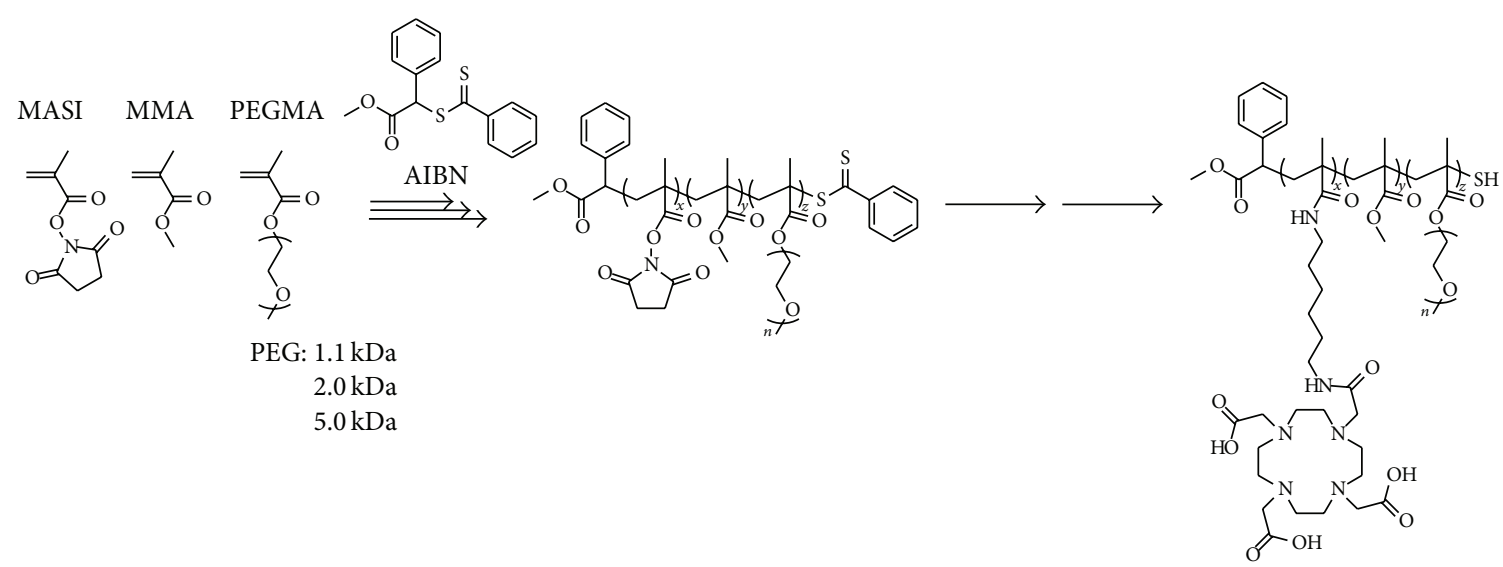

FIGURE 2: Scheme for poly(methyl methacrylate-co-methacryloxysuccinimide-graft-poly(ethylene glycol)).

undesired uptake at liver and spleen was high. However, owing to the combined effects of FR-mediated cell uptake and EPR effect, the micelle was accumulated at the tumor region with $2.1 \pm 0.3,3.2 \pm 0.7,6.0 \pm 1.9$, and $5.6 \pm 0.9 \% \mathrm{ID} / \mathrm{g}$ at $10 \mathrm{~min}$, $1 \mathrm{~h}, 4 \mathrm{~h}$, and $24 \mathrm{~h}$ from the administration, respectively.

2.1.2. Poly(methyl methacrylate-co-methacryloxysuccinimidegraft-poly(ethylene glycol)). To suppress undesired micelle uptake by RES, comb copolymers with branching various lengths of poly(ethylene glycol) (PEG) chains (1.1$5.0 \mathrm{kDa}$ ) were synthesized by standard reversible additionfragmentation chain-transfer (RAFT) polymerization conditions [29], and to the polymer terminal end, 1,4,7,10tetra-azacyclododecanetetra-acetic acid (DOTA) ligand was introduced as a chelator for radionuclides (Figure 2). The chelation with ${ }^{64} \mathrm{Cu}$ was carried out after preparation of polymeric micelles. Diameters of the micelles prepared from copolymers with PEG of 1.1, 2.0, and $5.0 \mathrm{kDa}$ were $9.7 \pm 1.1$, $17 \pm 2$, and $20 \pm 3 \mathrm{~nm}$, respectively.

Three types of ${ }^{64} \mathrm{Cu}$ labeled micelles were injected into rats from the tail vein and their biodistribution was determined by organ harvesting method so as to evaluate the effect of PEG chain length on the micelle biodistribution. Additionally, the imaging studies were carried out using small animal PET system. The $5.0 \mathrm{kDa}$ PEG micelle underwent a slow blood clearance, and $31 \pm 2 \%$ of the dose was still in blood at $48 \mathrm{~h}$ after injection, which was almost ten times and twice higher than that of $1.1 \mathrm{kDa}$ and $2.0 \mathrm{kDa}$ PEG micelles, respectively. Biodistribution trend in the liver was opposite to that observed in the blood. Liver uptake of 1.1, 2.0, and 5.0 $\mathrm{kDa}$ PEG micelles at $24 \mathrm{~h}$ from the injection was decreased in this order and to be ca. 4.0, 2.8, and $1.2 \% \mathrm{ID} / \mathrm{g}$, respectively. These results indicated that surface modification with PEG is important to control in vivo dynamics of the micelle, and prolongation of blood circulation time and low accumulation in excretory organs can be achieved by increased thickness of PEG shell.

2.1.3. Poly(lauryl methacrylate)-b-poly(N-(2-hydroxypropyl) methacrylamide). Amphiphilic copolymer consisted of hydrophobic poly(lauryl methacrylate) (poly(LMA)) and hydrophilic poly( $N$-(2-hydroxypropyl)methacrylamide) (poly (HPMA)) blocks that was synthesized via RAFT polymerization, and $\mathrm{PEG}_{2000}$ was incorporated into the side chain of the hydrophilic block with $0-11 \%$ modification ratio [30]. Further, the amphiphile was covalently labeled by radionuclides of ${ }^{18} \mathrm{~F}$. Polymeric micelle was prepared from the amphiphile, and the effects of the PEGylation on micelle size, biodistribution, and cell uptake behavior were evaluated. In animal experiments using rats, polymeric micelle with diameter of $38.1 \pm 2.1 \mathrm{~nm}$, which was prepared from amphiphilic block copolymer with 7\% PEGylation, exhibited the most favorable organ distribution pattern, showing highest blood circulation behavior as well as lowest undesired uptake at spleen and liver. Tumor cells of Walker 256 mammary carcinomas were clearly visualized by animal PET system after $2 \mathrm{~h}$ from the micelle dosage.

The group also synthesized random copolymers as well as block copolymers. Polymeric micelles were prepared from these copolymers, and their cellular uptake and biodistribution were evaluated using two different types of tumor models (AT1 prostate carcinoma and Walker-256 mammary carcinoma). They concluded that not only PEGylation, but also other numerous factors including molecular weight of the copolymers, polymer structure, size of the micelle, and characteristics of tumor affected the intratumor accumulation level of the micelle [31]. Therefore, preclinical screening to analyze polymer uptake for each individual patient is considered to be essential for each chemo- and radiotherapy using polymer-based DDS.

2.2. Core-Cross-Linked Type Polymeric Micelle (CCPM) for Enhanced Thermodynamic Stability. Compared with liposome, polymeric micelle is thermodynamically stable. This is because relatively long hydrophobic polymer chains can stabilize the molecular assemblies more than the hydrophobic interaction among alkyl chains of phospholipids. Aiming at further improvement of polymeric micelle stability, intermolecular cross-linking of copolymers via covalent bonds has been examined. 


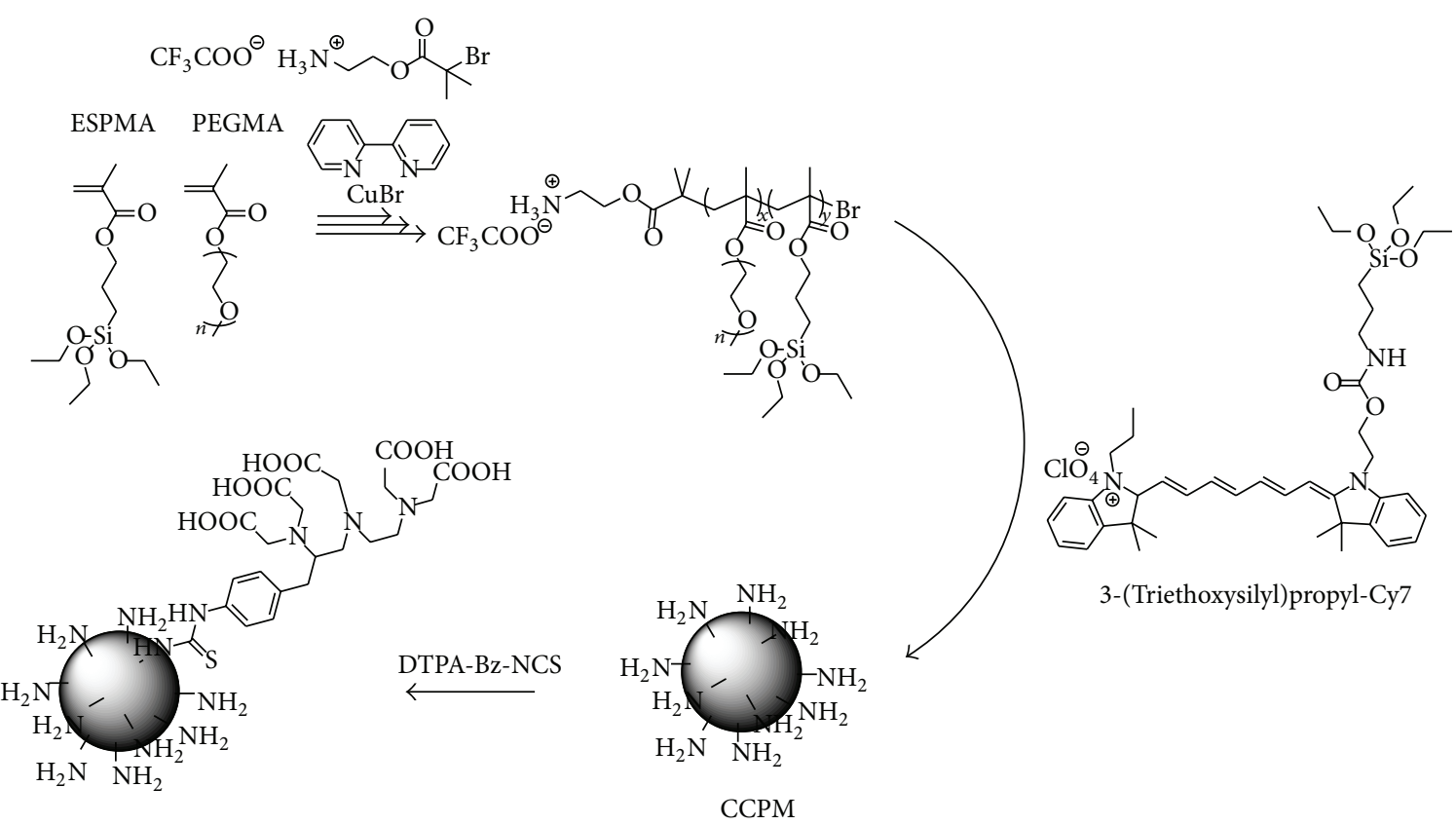

Figure 3: Preparation of core-cross-linked polymeric micelle (CCPM).

2.2.1. Poly(triethoxysilyl propylmethacrylate)-b-poly(PEGmethacrylate). Poly(triethoxysilyl propylmethacrylate)- $b$ poly(PEG-methacrylate) (PESPMA- $b$-PPEGPMA) was synthesized by atom transfer radical polymerization (ATRP). From the mixture of the polymer and 3-(trimethoxysilyl)propyl-Cy7, polymeric micelle was prepared by sol-gel process upon addition of acetic acid. The acid caused rapid hydrolysis of ethoxy silane precursors and subsequent cross-link of the PESPMA core with the Cy7 derivative via $\mathrm{Si}-\mathrm{O}$ bonds. Targeting the amino group, which is located at terminal end of hydrophilic block, DTPA was inserted on the surface of the core-cross-linked polymeric micelle (CCPM) and used for chelate formation with ${ }^{111}$ In (Figure 3 ). To the breast tumor cells of MDA-MB468 transplanted mice, ${ }^{111}$ InDTPA-CCPM with diameter of $24 \pm 8.9 \mathrm{~nm}$ was injected and $\gamma$-scintigraphy and NIRF optical imaging were performed [32]. CCPM showed prolonged blood circulation behavior $\left(t_{1 / 2, \alpha}=1.25 \mathrm{~h}, t_{1 / 2, \beta}=46.18 \mathrm{~h}\right)$ and passively accumulated at the tumor region (5.5\% ID/g at $48 \mathrm{~h}$ after injection). At $120 \mathrm{~h}$ from the dosage, tumor/blood and tumor/muscle signal ratios reached 4.44 and 28.0, respectively.

Characteristic point of CCPM is location of amino group on the surface, and therefore, it is possible to attach targeting ability to CCPM by ligand conjugation. For example, EphB4-binding peptide and synthetic somatostatin analogue of octreotide-conjugated CCPMs were prepared to detect EphB4-positive PC-3 M prostate and somatostatin receptor overexpressed glioblastoma U87 cells, respectively [33, 34]. When a cell undergoes apoptosis, phosphatidylserine is exposed on the cell surface. Then, annexin A5-conjugated CCPM, which binds strongly with phosphatidylserine, was also prepared [35]. Utilizing these ${ }^{111}$ In labeled CCPMs, dual
SPECT and NIRF imaging of the targeted region was accomplished. Further, time for accumulation of these ligandconjugated CCPMs to the targeted region could be shortened by specific bindings with corresponding receptors, and signal intensity ratio against background was also improved.

2.2.2. Poly(7-(2-methacryloyloxyethoxy)4-methylcoumarin)-b -poly(hydroxyethylmethacrylate)-b-poly(ethylene glycol). Copolymer consisting of one hydrophobic 7-(2-methacryloyloxyethoxy)-4-methylcoumarin (CMA) and two hydrophilic hydroxyethylmethacrylate (HEMA) and PEG blocks was also synthesized by Jensen et al. [36]. To hydroxyl groups of the HEMA block, DOTA or CB-TE2A was conjugated as a chelator for radioactive metal of ${ }^{64} \mathrm{Cu}$. After micelle formation by using self-assembling mechanism, the micelle dispersion was irradiated by UV light so as to cross-link 4-methylcoumarin moieties in the hydrophobic core. The cross-linked micelle showed higher stability in blood and was accumulated at transplanted tumor region (U87MG) of mice. After 22 and $46 \mathrm{~h}$ from the dosage of ${ }^{64} \mathrm{Cu}$ labeled micelles, tumor can be visualized.

\subsection{Micelle Formation from Biodegradable and Biocompatible Amphiphilic Polymers}

2.3.1. Poly(E-caprolactone)-b-poly(ethylene glycol). Polymeric micelle can be prepared from various amphiphilic polymers. From the view point that polymer nanoparticles are applied as carrier for DDS, utilization of biodegradable and biocompatible amphiphilic polymers should take priority. Then, poly( $\varepsilon$-caprolactone), which is representative biodegradable 


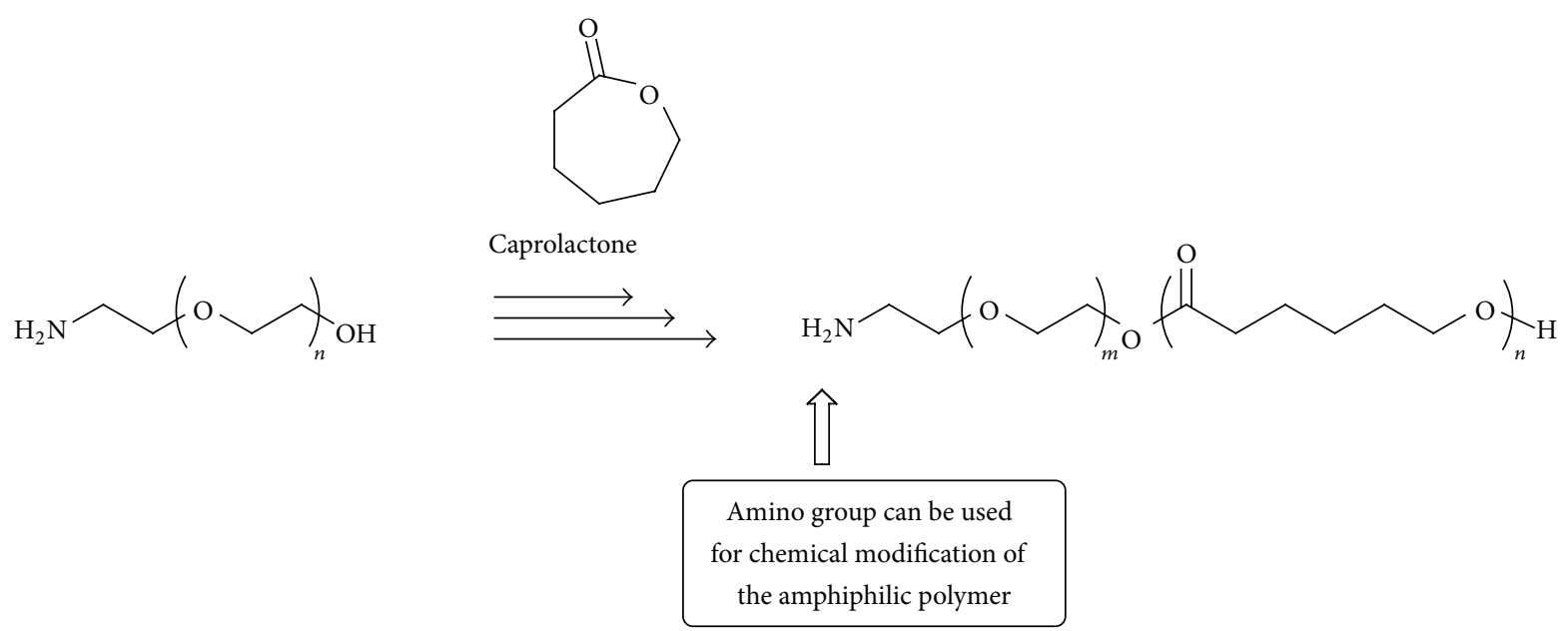

FIGURE 4: Amphiphilic poly( $\varepsilon$-caprolactone)-b-poly(ethylene glycol) for micelle preparation.

polymer connecting through ester linkages, was selected as hydrophobic block of the amphiphilic polymer (Figure 4) [37]. For the chelate formation with ${ }^{111} \mathrm{In}$, terminal end of the amphiphilic polymer is modified by diethylene triamine penta-acetic acid (DTPA), which is a well-known chelator to form stable complexes with metals. From DTPA modified poly( $\varepsilon$-caprolactone)- $b$-poly(ethylene glycol) (PCL- $b$-PEG), polymer micelle was prepared and then radionuclide ${ }^{111} \mathrm{In}$ was chelated to DTPA [38]. To the tumor-bearing mice, the ${ }^{111}$ In labeled micelle with diameter of ca. $60 \mathrm{~nm}$ was injected, and its biodistribution and pharmacokinetics were evaluated by the organ harvesting method and SPECT/CT in vivo imaging system. The micelle was passively accumulated at the tumor region $(9 \pm 2 \% \mathrm{ID} / \mathrm{g})$, and transplanted tumor could be imaged by SPECT.

On a cell surface of various types of epithelial cancers including lung and breast, epidermal growth factor receptor (EGFR) is known to be overexpressed. The micelle surface was functionalized by conjugating EGF to terminal amino group of the amphiphile so as to improve the ${ }^{111}$ In labeled micelle delivering efficiency to the targeted tumor region [39]. Compared with the accumulation of the nontargeting micelle (EGF-), in vivo cell uptake and cell membrane binding of the EGF modified micelle (EGF+) to tumors overexpressing EGFR were significantly enhanced $(P<0.05)$.

${ }^{111}$ In can be also utilized as therapeutic nucleotide as emitter of auger electrons [40]. Using the EGF modified micelle, effect of auger electron therapy against EGFR-positive breast cancer cells was performed [41]. In this research, three types of human breast cancer cell cultures of MDA-MB-468 $\left(1 \times 10^{6} \mathrm{EGFR} /\right.$ cell $), \mathrm{MDA}-\mathrm{MB}-231\left(2 \times 10^{5} \mathrm{EGFR} /\right.$ cell $)$, and MCF-7 $\left(1 \times 10^{4} \mathrm{EGFR} /\right.$ cell $)$ were used. Correlated with the density of EGFR expression level on these cancer cells, EGFRmediated uptake of the micelle (EGF+) was increased. In in vitro cell survival assay, cell number of MDA-MB-468 was significantly decreased after $21 \mathrm{~h}$ from the treatment by $1 \mathrm{MBq}$ of ${ }^{111}$ In-DTPA modified micelle (EGF+). However, the micelle showed no cytotoxicity against MCF-7 with low EGFR expression level.

On the cell surface of breast cancer, it is known to express different levels of HER2. Then, ${ }^{111}$ In labeled micelle, whose surface is modified by HER2 specific antibody (trastuzumab fab) instead of the EGF sequence, was prepared, and its therapeutic performance was also evaluated [42, 43]. Targeting the gastric cancer diagnosis, glucose-regulated protein 78 (GRP78) binding peptide modified micelle was attached to the ${ }^{111}$ In labeled micelle surface, and in vivo SPECT imaging was accomplished [44]. In short, polymeric micelle can be arranged in accordance with the intended uses.

Preparation of multifunctional micelles for photothermal therapy (PTT) is also conducted [45]. To the hydrophobic core of the micelle prepared from DTPA modified PCL- $b$ PEG, near-infrared (NIR) dye of IR-780 iodide was encapsulated as signal agent for NIRF imaging and photosensitizer for PTT. Further, ${ }^{188}$ Re was chelated to DTPA as a signal source for SPECT imaging. The micelle was designed so that in vivo dynamics after dosage can be traced by SPECT system. Based on the real time monitoring of the micelle integration to the targeted tumor region, NIR light irradiation could be carried out.

Characters of molecular assemblies can be controlled by changing polymer architecture and its hydrophilichydrophobic balance. For example, thermosensitive hydrogel containing a therapeutic radionuclide $\left({ }^{188} \mathrm{Re}\right.$-Tin colloid) and a chemotherapeutic drug (liposomal doxorubicin) was prepared from PCL- $b$-PEG- $b$-PCL triblock copolymer [46]. The thermosensitive gel was intratumorally administrated to the hepatocellular carcinoma, and the therapeutic effect was evaluated. At the tumor region, liposomal doxorubicin and ${ }^{188}$ Re-Tin colloid were released slowly and steadily. The therapeutic effect was greater than the cases in which either component was individually used, and the synergetic effect against tumor growth was confirmed. 


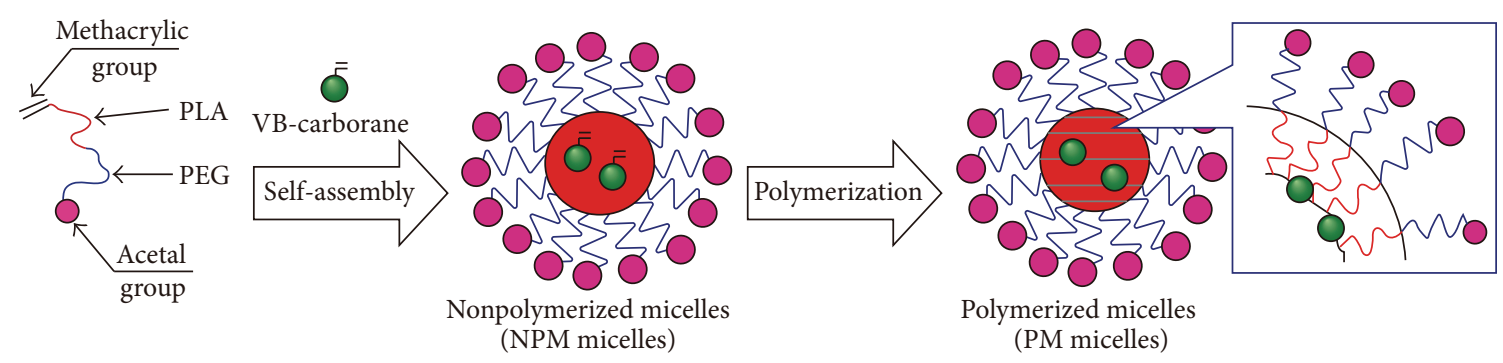

FIGURE 5: Schematic illustration of ${ }^{10} \mathrm{~B}$-enriched micelle preparation from acetal-PEG- $b$-PLA-MA and polymerizable VB-carborane. Reprinted from Biomaterials, 2012, 33, 3568-3577. S. Sumitani, M. Oishi, T. Yaguchi, H. Murotani, Y. Horiguchi, M. Suzuki, K. Ono, H. Yanagie, and Y. Nagasaki. "Pharmacokinetics of core-polymerized, boron-conjugated micelles designed for boron neutron capture therapy for cancer." Copyright (2012), with permission from Elsevier.

2.3.2. Poly(ethylene glycol)-b-poly(lactic acid). Poly(lactic acid) (PLA) is representative biodegradable polymer connecting through ester linkage. Polymeric micelle prepared from PEG- $b$-PLA is also evaluated and used as nanoordered carriers for DDS by various research groups [47].

Nonradioactive ${ }^{10} \mathrm{~B}$ is known to produce $\alpha$ particles and ${ }^{7} \mathrm{Li}$ nuclei with ca. $2.3 \mathrm{MeV}$ of energy by the capture reaction of thermal neutrons, and therefore, utilization ${ }^{10} \mathrm{~B}$ on boron neutron capture therapy (BNCT) is investigated. BNCT could make it possible to irradiate directly targeted tumor region with suppressing nonspecific exposure. However, restricted neutron source for the treatment is one of the major problems for practical usages. Sumitani et al. evaluated utilization of PEG- $b$-PLA micelle to improve delivering efficiency of boron derivatives to the targeted tumor region $[48,49]$. In this study, polymeric micelle was prepared from amphiphilic PEG- $b$-PLA polymer derivative of acetal-PEG$b$-PLA-MA, whose PEG and PLA terminal ends are modified by acetal and methacryloyl groups, respectively. To the micelle, 1-(4-vinylbenzyl)-closo-carborane (VB-carborane) and azobisisobutyronitrile (AIBN) mixtures were encapsulated, and core cross-polymerized and boron-conjugated micelles were prepared by the free radical polymerization method (Figure 5). To the tumor transplanted mice, the ${ }^{10} \mathrm{~B}$ enriched micelle was administrated, and neutron irradiation was performed after $24 \mathrm{~h}$ from the dosage. The ${ }^{10} \mathrm{~B}$-enriched micelle was accumulated at the tumor region and showed significant therapeutic effects after the neutron irradiation.

2.3.3. Poly(sarcosine)-b-poly(L-lactic acid). Amphiphilic polydepsipeptide of (sarcosine) $)_{70}-b$-(L-lactic acid $)_{30}$ is known to form polymeric micelle with diameter of ca. $35 \mathrm{~nm}$, and the polymeric micelle was named as "Lactosome" $[18,50]$. Sarcosine (Sar), $\mathrm{N}$-methyl glycine in other words, is natural amino acid, and its homopolymer shows high solubility against aqueous solution like PEG. Therefore, polymeric micelle whose surface is covered with poly(Sar) was also expected to show a prolonged blood circulation behavior with low undesired accumulation by reticuloendothelial system (RES).

As a radionuclide for PET imaging, hydrophobized ${ }^{18} \mathrm{~F}$ by attaching PLLA chain $\left(\left[{ }^{18} \mathrm{~F}\right] \mathrm{SFB}\right.$ labeled poly(L-lactic acid) of $30 \mathrm{mer}$ ) was encapsulated into the core region of the polymeric micelle by using hydrophobic interactions [51]. The ${ }^{18} \mathrm{~F}$ labeled Lactosome was administrated from the tail vein to the tumor transplanted mice, and PET images were taken after $6 \mathrm{~h}$ from the dosage. Lactosome showed a good blood circulation behavior owing to the surface modification with hydrophilic poly(sarcosine) chains. Therefore, signal intensity at organs with high blood flows was high. However, the accumulated signal in the transplanted tumor region could be detected. Since Lactosome surface was not specifically modified by ligands, Lactosome is considered to be passively accumulated to the tumor region by the EPR effect.

As a therapeutic radionuclide, $\left[{ }^{131} \mathrm{I}\right] \mathrm{SIB}$ labeled PLLA was encapsulated into the Lactosome as $\beta^{-}$ray emitter by the same approach with the previous ${ }^{18} \mathrm{~F}$ compound for PET imaging. To the tumor transplanted mice, which were preliminary treated with preethanol injection therapy (PEIT), ${ }^{131}$ I labeled Lactosome of $200 \mathrm{MBq} / \mathrm{kg}$ was injected and time courses of tumor growth were observed [52]. As a result, ${ }^{131} \mathrm{I}$ labeled Lactosome could be delivered to the tumor region, and the tumor growth was significantly suppressed.

2.4. Accelerated Blood Clearance (ABC) Phenomenon of Lactosome. Lactosome is a candidate nanoordered carrier for drug and/or imaging agent delivery. On medicinal usages, nanocarriers are expected to show unaltered disposition on multiple administrations. However, production of antiLactosome antibody occurred after 3 days from the first Lactosome administration, and the antibody production kept high level for 6 months [53]. Lactosome on second dosage was opsonized by the anti-Lactosome antibody soon after the administration and entrapped by reticuloendothelial system (RES). This phenomenon is named as accelerated blood clearance $(\mathrm{ABC})$ phenomenon of Lactosome, and resembled phenomenon is sometimes observed on PEGylated materials $[54,55]$.

The production amounts of the anti-Lactosome IgM were revealed to be inversely correlated with that of the first Lactosome dosage. When first Lactosome dosage is over $150 \mathrm{mg} / \mathrm{kg}$, the Lactosome $\mathrm{ABC}$ phenomenon 


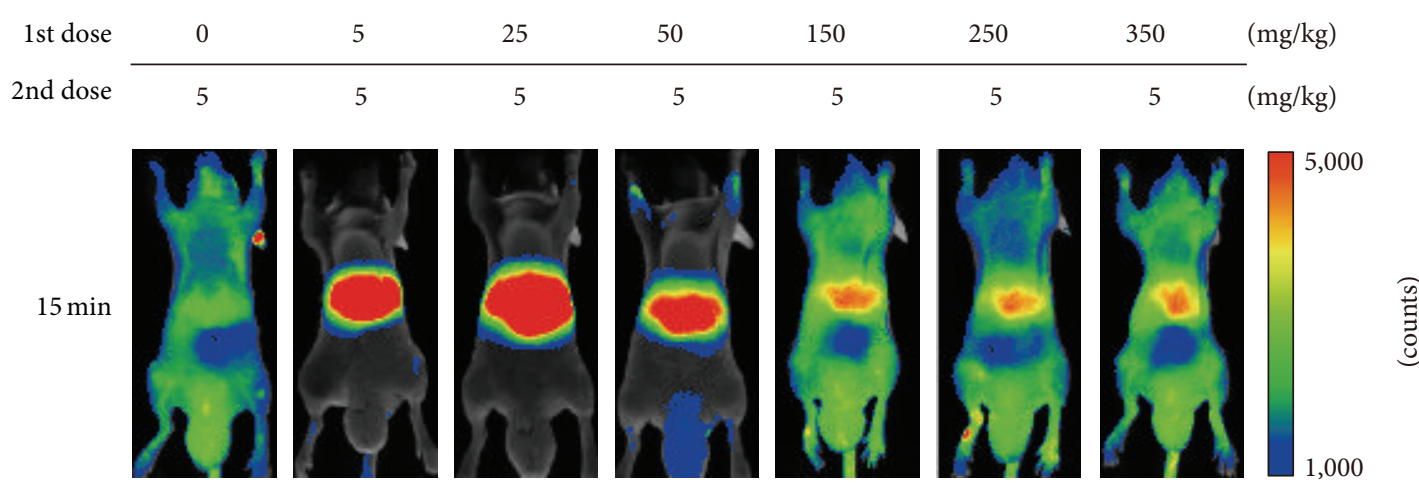

(a)
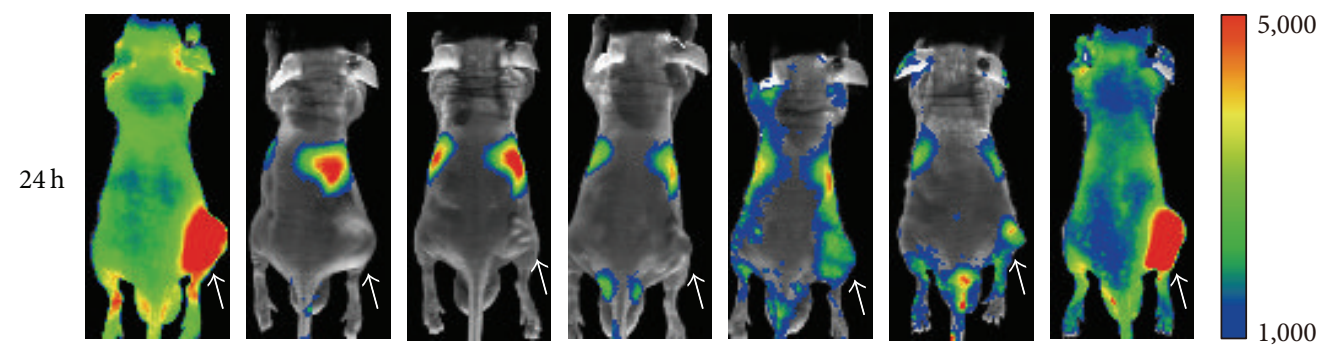

离
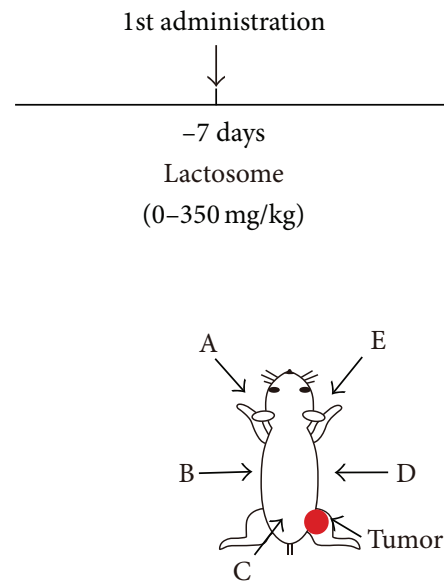

(b)

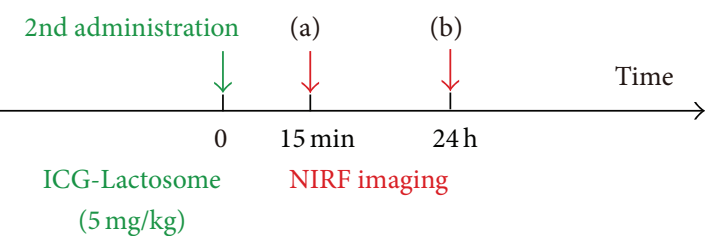

(c)

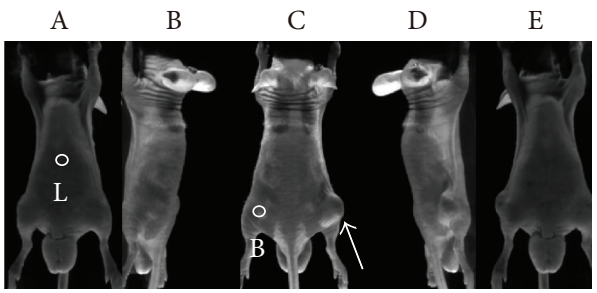

(d)

Figure 6: Effect of the first Lactosome dose on the Lactosome ABC phenomenon. NIRF images of mice at (a) 15 min (view from A in Figure 6(d)) and (b) $24 \mathrm{~h}$ (view from C in Figure 6(d)) after ICG-Lactosome of 2 nd dose. Lactosomes (5, 25, and 50 mg/kg/100 $\mu \mathrm{L}$ and 150, 250, and $350 \mathrm{mg} / \mathrm{kg} / 200 \mu \mathrm{L}$ ) were injected into the mice 7 days before the ICG-Lactosome administration. SUIT-2/pEF/luc cells were transplanted at the right femoral region of mice, in which tumor sites are indicated by white arrows. The fluorescein signal ranges were set to be the same for all the images from max count 5000 to min count 1000. (c) Time schedule for the NIRF imaging. Black and green arrows indicate the injection time points of Lactosome and ICG-Lactosome, respectively. NIRF imaging was performed at red arrows. (d) NIRF images were taken using Shimadzu Clairvivo OPT, which can take five images from different directions (A-E) with one time shot. The white circles indicate positions of ROI (L: liver; B: background). Reprinted from Biochemica et Biophysica Acta (BBA)-General Subjects, 2013, 1830, 4046-4052., E. Hara, A. Makino, K. Kurihara, M. Sugai, A. Shimizu, I. Hara, E. Ozeki, and S. Kimura. "Evasion from accelerated blood clearance of nanocarrier named as "Lactosome" induced by excessive administration of Lactosome." Copyright (2013), with permission from Elsevier B.V.

could be suppressed by induced immunological tolerance (Figure 6). Further, even if anti-Lactosome IgM is once produced, the Lactosome ABC phenomenon can be evaded by dosing Lactosome over $50 \mathrm{mg} / \mathrm{kg}$. Importantly, acute toxicity was not observed at the Lactosome dosage amount [56].
Recently the production of anti-Lactosome IgM has been found to be suppressed by increasing the local density of poly(sarcosine) chains on the micelle surface. Higher local density of the surrounding hydrophilic polymer chains should be related with prevention of the interaction between micelles and B cell receptors [57]. 


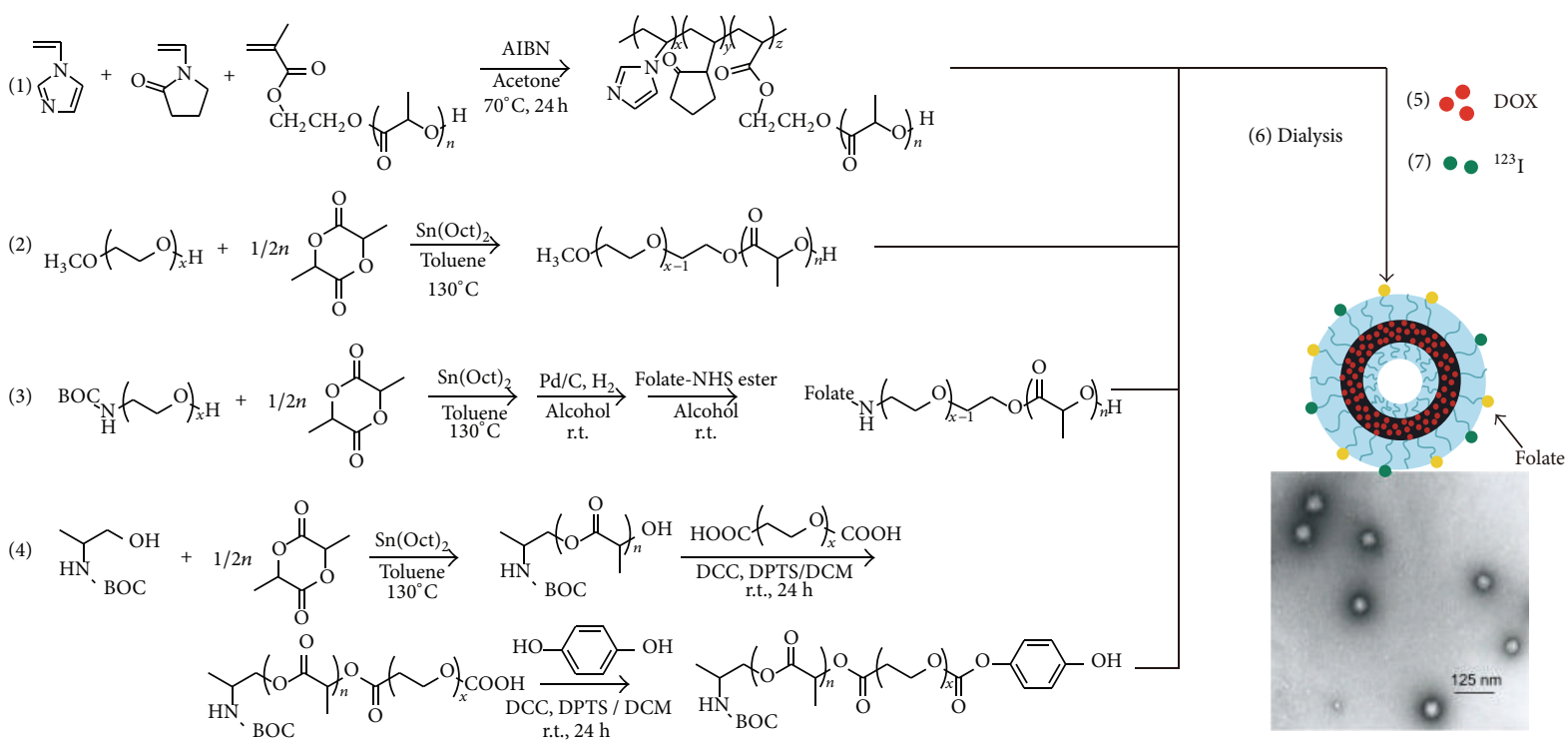

FIGURE 7: Representation of multifunctional hollow nanoparticles and their TEM image. Reprinted from Biomaterials, 2011, 32, 2213-2221., P. L. Lu, Y. C. Chen, T. W. Ou, H. H. Chen, H. C. Tsai, C. J. Wen, C. L. Lo, S. P. Wey, K. J. Lin, T. C. Yen, and G. H. Hsiue. "Multifunctional hollow nanoparticles based on graft-diblock copolymers for doxorubicin delivery." Copyright (2011), with permission from Elsevier.

Further, it is still unclear whether the $\mathrm{ABC}$ phenomenon is a general phenomenon for nanoparticles. However, to develop repeatedly injectable nanoordered carriers is essential for its general usages.

\section{Vesicular Assemblies}

The number of examples using vesicular assemblies as a carrier for DDS in nuclear medicinal field is relatively limited. It may be because of more difficult preparation of vesicular assemblies than polymeric micelles.

$\mathrm{Lu}$ et al. prepared multifunctional hollow nanoparticle from a mixture of doxorubicin hydrochloride (DOX-HCl), $\mathrm{mPEG}_{5000}-b$-poly(D,L-lactic acid) ${ }_{1510}\left(\mathrm{mPEG}_{5000}-b-\mathrm{PLA}_{1510}\right)$, folate-PEG $\mathrm{P}_{5000}-b-\mathrm{PLA}_{1200}$, phenolic ester- $\mathrm{PEG}_{5000}-b-\mathrm{PLA}_{650}$, and poly $(N \text {-vinylimidazole-co- } N \text {-vinylpyrrolidone })_{9600^{-}} g$ $\mathrm{PLA}_{4900}$ (Figure 7) [58]. The hollow nanoparticle is designed to show sensitivity against intracellular $\mathrm{pH}$ changes by using $\mathrm{pH}$ sensitive character of $\mathrm{N}$-vinylimidazole (NVI) (pKa values of NVI are around 6.0). Depending on the $\mathrm{pH}$ changes of the dispersion, its diameter was reversibly changed between $90 \mathrm{~nm}(\mathrm{pH} 7.4)$ and $80 \mathrm{~nm}(\mathrm{pH} \mathrm{5.0)}$ ), and rate of encapsulated DOX-HCl release could be accelerated under weak acidic conditions. Extracellular matrix of the tumor region is known to be in a weakly acidic condition, and therefore, the DOX-HCl is expected to be released selectively at the tumor region. Folate- $\mathrm{PEG}_{5000}-b-\mathrm{PLA}_{1200}$ provided the nanoparticle with a tumor-targeting ability, and phenolic ester-PEG $\mathrm{P}_{5000}-b-\mathrm{PLA}_{650}$ was used for modification of the nanoparticle with ${ }^{123} \mathrm{I}$ by the iodogen method.

To the tumor transplanted mice, the multifunctional hollow nanoparticle was administrated, and the time course of tumor growth was observed. Dynamics of the nanoparticle at $0.5-6 \mathrm{~h}$ from the administration were noninvasively visualized by SPECT. Shortly after the administration, the nanoparticle was accumulated at the tumor region with a high level due to the folate-binding protein effect. Compared with the case of free DOX-HCl, the tumor growth was effectively suppressed with a minimum body weight loss.

\section{Conclusion}

In particular in these ten years, application of polymeric nanoparticles as a carrier for tumor-targeted drug delivery system (DDS) is expanded to nuclear medicinal fields. It is a tremendous advantage to apply polymeric nanoparticles for DDS, because in vivo pharmacokinetics can be well controlled by suitable selections about their size, shape, and surface characters and can be free from the loading imaging or therapeutic compounds. Therefore, when the same nanoparticle is used as a carrier for imaging and therapeutic purposes, diagnostic outcomes can directly predict the treatment efficiency of the loading therapeutic agent on the nanoparticle. Further, imaging results before and after chemotherapy can be used for prediction and evaluation of the therapeutic effect, respectively. In order to improve personal medical treatment, it is essential to dose the therapeutic agent properly to each patient. Polymeric micelles and vesicles endowed with two functions for diagnosis and therapy are expected to be potential materials for future personalized medicine, and these research areas are especially named as "nanotheranostics."

However, there are many research problems to be dissolved. For example, almost all types of nanoparticles are designed to evade from undesired capture by reticuloendothelial system (RES) and to show a prolonged blood circulation behavior. Radioactivity is decreased with distinct half-life of each radionuclide, and time period, which can 
be effectively used, is limited. Therefore, radionuclides with relatively long half-life period such as ${ }^{64} \mathrm{Cu}$ for PET and ${ }^{111} \mathrm{In}$ for SPECT are mainly selected for radiolabeling of polymer nanoparticles. Further, how to control radiation exposure is also extremely important in nuclear medicinal fields. For these reasons, purpose of polymer nanoparticle DDS is mainly diagnosis, which can be performed by relatively low radioactivity, and research trials on inner radiotherapy are small in number. To accomplish practical usages of polymer nanoparticles as carriers for inner radiotherapy, (1) further improvement of drug delivery efficiency and (2) reduction of radiation exposure at radiosensitive organs such as bone marrow are essential by controlling the nanoparticles in vivo dynamics. It has already been revealed that to create synergetic therapeutic effect is possible by combined usages of therapeutic nanoparticle with conventional therapies, and therefore, therapeutic nanoparticles are now in an early phase of development.

Another problem for the view point of commercialization is how to ensure the quality of the nanoparticle. The number of examples utilizing polymeric nanoparticles as carriers for DDS in human clinical practice is limited. Therefore, to make rules for polymer nanoparticle production and their clinical studies is also considered to be important and started in government regulatory agencies [59].

There are many problems to be dissolved; however, application and commercialization researches on theranostic nanoparticles are expected surely to make future progresses in nuclear medicinal fields.

\section{Conflict of Interests}

The authors declare that there is no conflict of interests regarding the publication of this paper.

\section{Acknowledgment}

This study was partially supported by Coordination, Support and Training Program for Translational Research by MEXT, Japan.

\section{References}

[1] R. Hao, R. J. Xing, Z. C. Xu, Y. L. Hou, S. Goo, and S. H. Sun, "Synthesis, functionalization, and biomedical applications of multifunctional magnetic nanoparticles," Advanced Materials, vol. 22, no. 25, pp. 2729-2742, 2010.

[2] P. Horcajada, R. Gref, T. Baati et al., "Metal-organic frameworks in biomedicine," Chemical Reviews, vol. 112, no. 2, pp. 1232-1268, 2012.

[3] D. Peer, J. M. Karp, S. Hong, O. C. Farokhzad, R. Margalit, and R. Langer, "Nanocarriers as an emerging platform for cancer therapy," Nature Nanotechnology, vol. 2, no. 12, pp. 751-760, 2007.

[4] M. Ferrari, "Cancer nanotechnology: opportunities and challenges," Nature Reviews Cancer, vol. 5, no. 3, pp. 161-171, 2005.

[5] R. K. Jain and T. Stylianopoulos, "Delivering nanomedicine to solid tumors," Nature Reviews Clinical Oncology, vol. 7, no. 11, pp. 653-664, 2010.
[6] Z. Jiao, X. Wang, and Z. Chen, "Advance of amphiphilic block copolymeric micelles as drug delivery," Asian Journal of Chemistry, vol. 25, no. 4, pp. 1765-1769, 2013.

[7] M. Elsabahy and K. L. Wooley, "Design of polymeric nanoparticles for biomedical delivery applications," Chemical Society Reviews, vol. 41, no. 7, pp. 2545-2561, 2012.

[8] Z. Ge and S. Liu, "Functional block copolymer assemblies responsive to tumor and intracellular microenvironments for site-specific drug delivery and enhanced imaging performance," Chemical Society Reviews, vol. 42, no. 17, pp. 7289-7325, 2013.

[9] S. Ganta, H. Devalapally, A. Shahiwala, and M. Amiji, "A review of stimuli-responsive nanocarriers for drug and gene delivery," Journal of Controlled Release, vol. 126, no. 3, pp. 187-204, 2008.

[10] J. H. Park, S. Lee, J.-H. Kim, K. Park, K. Kim, and I. C. Kwon, "Polymeric nanomedicine for cancer therapy," Progress in Polymer Science, vol. 33, no. 1, pp. 113-137, 2008.

[11] J. Fang, H. Nakamura, and H. Maeda, “The EPR effect: unique features of tumor blood vessels for drug delivery, factors involved, and limitations and augmentation of the effect," Advanced Drug Delivery Reviews, vol. 63, no. 3, pp. 136-151, 2011.

[12] A. K. Iyer, G. Khaled, J. Fang, and H. Maeda, "Exploiting the enhanced permeability and retention effect for tumor targeting," Drug Discovery Today, vol. 11, no. 17-18, pp. 812-818, 2006.

[13] H. Maeda, J. Wu, T. Sawa, Y. Matsumura, and K. Hori, “Tumor vascular permeability and the EPR effect in macromolecular therapeutics: a review," Journal of Controlled Release, vol. 65, no. 1-2, pp. 271-284, 2000.

[14] L. Brannon-Peppas and J. O. Blanchette, "Nanoparticle and targeted systems for cancer therapy," Advanced Drug Delivery Reviews, vol. 64, pp. 206-212, 2012.

[15] S. P. Egusquiaguirre, M. Igartua, R. M. Hernández, and J. L. Pedraz, "Nanoparticle delivery systems for cancer therapy: advances in clinical and preclinical research," Clinical and Translational Oncology, vol. 14, no. 2, pp. 83-93, 2012.

[16] H. Tanisaka, S. Kizaka-Kondoh, A. Makino, S. Tanaka, M. Hiraoka, and S. Kimura, "Near-infrared fluorescent labeled peptosome for application to cancer imaging," Bioconjugate Chemistry, vol. 19, no. 1, pp. 109-117, 2008.

[17] Y. Chen and X. Li, "Near-infrared fluorescent nanocapsules with reversible response to thermal/PH modulation for optical imaging," Biomacromolecules, vol. 12, no. 12, pp. 4367-4372, 2011.

[18] A. Makino, S. Kizaka-Kondoh, R. Yamahara et al., "Nearinfrared fluorescence tumor imaging using nanocarrier composed of poly(l-lactic acid)-block-poly(sarcosine) amphiphilic polydepsipeptide," Biomaterials, vol. 30, no. 28, pp. 5156-5160, 2009.

[19] R. Weissleder, "A clearer vision for in vivo imaging," Nature Biotechnology, vol. 19, no. 4, pp. 316-317, 2001.

[20] D. L. Bailey and K. P. Willowson, "Quantitative SPECT/CT: SPECT joins PET as a quantitative imaging modality," European Journal of Nuclear Medicine and Molecular Imaging, vol. 41, no. 1, pp. 17-25, 2013.

[21] Y. Li, S. M. A. Rizvi, J. M. Blair et al., "Antigenic expression of human metastatic prostate cancer cell lines for in vitro multipletargeted $\alpha$-therapy with 213Bi-conjugates," International Journal of Radiation Oncology Biology Physics, vol. 60, no. 3, pp. 896908, 2004.

[22] B. Cornelissen, S. Darbar, R. Hernandez et al., "ErbB-2 blockade and prenyltransferase inhibition alter epidermal growth factor 
and epidermal growth factor receptor trafficking and enhance 111In-DTPA-hEGF auger electron radiation therapy," Journal of Nuclear Medicine, vol. 52, no. 5, pp. 776-783, 2011.

[23] D. L. Costantini, C. Chan, Z. L. Cai, K. A. Vallis, and R. M. Reilly, " ${ }^{111}$ In-labeled trastuzumab (Herceptin) modified with nuclear localization sequences (NLS): an auger electronemitting radiotherapeutic agent for HER2/neu-amplified breast cancer," The Journal of Nuclear Medicine, vol. 48, no. 8, pp. 13571368, 2007.

[24] B. Cambien, P. R. Franken, A. Lamit et al., "(TcO4-)-Tc-99m-, auger-mediated thyroid stunning: dosimetric requirements and associated molecular events," PLoS ONE, vol. 9, no. 3, Article ID e92729, 2014.

[25] W. D. Bloomer and S. J. Adelstein, "5-125I-iododeoxyuridine as prototype for radionuclide therapy with Auger emitters," Nature, vol. 265, no. 5595, pp. 620-621, 1977.

[26] R. Rossin, D. P. J. Pan, K. Qi et al., "64Cu-labeled folateconjugated shell cross-linked nanoparticles for tumor imaging and radiotherapy: synthesis, radiolabeling, and biologic evaluation," Journal of Nuclear Medicine, vol. 46, no. 7, pp. 1210-1218, 2005.

[27] K. Qi, Q. Ma, E. E. Remsen, C. G. Clark Jr., and K. L. Wooley, "Determination of the bioavailability of biotin conjugated onto shell cross-linked (SCK) nanoparticles," Journal of the American Chemical Society, vol. 126, no. 21, pp. 6599-6607, 2004.

[28] J. Sudimack and R. J. Lee, “Targeted drug delivery via the folate receptor," Advanced Drug Delivery Reviews, vol. 41, no. 2, pp. 147-162, 2000.

[29] E. D. Pressly, R. Rossin, A. Hagooly et al., "Structural effects on the biodistribution and positron emission tomograpgy (PET) imaging of well-defined 64Cu-labeled nanoparticles comprised of amphiphilic block graft copolymers," Biomacromolecules, vol. 8, no. 10, pp. 3126-3134, 2007.

[30] M. Allmeroth, D. Moderegger, D. Gündel et al., "PEGylation of HPMA-based block copolymers enhances tumor accumulation in vivo: a quantitative study using radiolabeling and positron emission tomography," Journal of Controlled Release, vol. 172, no. 1, pp. 77-85, 2013.

[31] M. Allmeroth, D. Moderegger, D. Gündel et al., "HPMA-LMA copolymer drug carriers in oncology: an in vivo PET study to assess the tumor line-specific polymer uptake and body distribution," Biomacromolecules, vol. 14, no. 9, pp. 3091-3101, 2013.

[32] Z. Yang, S. Zheng, W. J. Harrison et al., "Long-circulating nearinfrared fluorescence core-cross-linked polymeric micelles: synthesis, characterization, and dual nuclear/optical imaging," Biomacromolecules, vol. 8, no. 11, pp. 3422-3428, 2007.

[33] R. Zhang, C. Xiong, M. Huang et al., "Peptide-conjugated polymeric micellar nanoparticles for Dual SPECT and optical imaging of EphB4 receptors in prostate cancer xenografts," Biomaterials, vol. 32, no. 25, pp. 5872-5879, 2011.

[34] Y. Hong, H. Zhu, J. Hu et al., "Synthesis and radiolabeling of 111In-core-cross linked polymeric micelle-octreotide for nearinfrared fluoroscopy and single photon emission computed tomography imaging," Bioorganic and Medicinal Chemistry Letters, vol. 24, no. 12, pp. 2781-2785, 2014.

[35] R. Zhang, W. Lu, X. Wen et al., "Annexin A5-conjugated polymeric micelles for dual SPECT and optical detection of apoptosis," Journal of Nuclear Medicine, vol. 52, no. 6, pp. 958964, 2011.
[36] A. I. Jensen, T. Binderup, P. Kumar Ek, A. Kjær, P. H. Rasmussen, and T. L. Andresen, "Positron emission tomography based analysis of long-circulating cross-linked triblock polymeric micelles in a U87MG mouse xenograft model and comparison of DOTA and CB-TE2A as chelators of copper-64," Biomacromolecules, vol. 15, no. 5, pp. 1625-1633, 2014.

[37] M. Okada, "Chemical syntheses of biodegradable polymers," Progress in Polymer Science, vol. 27, no. 1, pp. 87-133, 2002.

[38] B. Hoang, H. Lee, R. M. Reilly, and C. Allen, "Noninvasive monitoring of the fate of 11lin-labeled block copolymer micelles by high resolution and high sensitivity microSPECT/CT imaging," Molecular Pharmaceutics, vol. 6, no. 2, pp. 581-592, 2009.

[39] H. Lee, B. Hoang, H. Fonge, R. M. Reilly, and C. Allen, "In vivo distribution of polymeric nanoparticles at the whole-body, tumor, and cellular levels," Pharmaceutical Research, vol. 27, no. 11, pp. 2343-2355, 2010.

[40] R. M. Reilly, R. Kiarash, R. G. Cameron et al., "111In-labeled EGF is selectively radiotoxic to human breast cancer cells overexpressing EGFR," Journal of Nuclear Medicine, vol. 41, no. 3, pp. 429-438, 2000.

[41] H. Fonge, H. Lee, R. M. Reilly, and C. Allen, "Multifunctional block copolymer micelles for the delivery of 11lin to EGFRpositive breast cancer cells for targeted Auger electron radiotherapy," Molecular Pharmaceutics, vol. 7, no. 1, pp. 177-186, 2010.

[42] B. Hoang, R. M. Reilly, and C. Allen, "Block copolymer micelles target auger electron radiotherapy to the nucleus of HER2positive breast cancer cells," Biomacromolecules, vol. 13, no. 2, pp. 455-465, 2012.

[43] B. Hoang, S. N. Ekdawi, R. M. Reilly, and C. Allen, "Active targeting of block copolymer micelles with trastuzumab fab fragments and nuclear localization signal leads to increased tumor uptake and nuclear localization in HER2-overexpressing xenografts," Molecular Pharmaceutics, vol. 10, no. 11, pp. 42294241, 2013.

[44] C.-C. Cheng, C.-F. Huang, A.-S. Ho et al., "Novel targeted nuclear imaging agent for gastric cancer diagnosis: glucoseregulated protein 78 binding peptide-guided ${ }^{111}$ In-labeled polymeric micelles," International Journal of Nanomedicine, vol. 8, pp. 1385-1391, 2013.

[45] C.-L. Peng, Y.-H. Shih, P.-C. Lee, T. M.-H. Hsieh, T.-Y. Luo, and M.-J. Shieh, "Multimodal image-guided photothermal therapy mediated byl88Re-labeled micelles containing a cyanine-type photosensitizer," ACS Nano, vol. 5, no. 7, pp. 5594-5607, 2011.

[46] C.-L. Peng, Y.-H. Shih, K.-S. Liang et al., "Development of in situ forming thermosensitive hydrogel for radiotherapy combined with chemotherapy in a mouse model of hepatocellular carcinoma," Molecular Pharmaceutics, vol. 10, no. 5, pp. 1854-1864, 2013.

[47] D. H. Yu, Q. Lu, J. Xie, C. Fang, and H. Z. Chen, "Peptideconjugated biodegradable nanoparticles as a carrier to target paclitaxel to tumor neovasculature," Biomaterials, vol. 31, no. 8, pp. 2278-2292, 2010.

[48] S. Sumitani, M. Oishi, T. Yaguchi et al., "Pharmacokinetics of core-polymerized, boron-conjugated micelles designed for boron neutron capture therapy for cancer," Biomaterials, vol. 33, no. 13, pp. 3568-3577, 2012.

[49] S. Sumitani and Y. Nagasaki, "Boron neutron capture therapy assisted by boron-conjugated nanoparticles," Polymer Journal, vol. 44, no. 6, pp. 522-530, 2012.

[50] A. Makino, E. Hara, I. Hara et al., "Control of in vivo blood clearance time of polymeric micelle by stereochemistry of 
amphiphilic polydepsipeptides," Journal of Controlled Release, vol. 161, no. 3, pp. 821-825, 2012.

[51] F. Yamamoto, R. Yamahara, A. Makino et al., "Radiosynthesis and initial evaluation of $18 \mathrm{~F}$ labeled nanocarrier composed of poly(L-lactic acid)-block-poly(sarcosine) amphiphilic polydepsipeptide," Nuclear Medicine and Biology, vol. 40, no. 3, pp. 387394, 2013.

[52] E. Hara, A. Makino, K. Kurihara et al., "Radionuclide therapy using nanoparticle of131I-Lactosome in combination with percutaneous ethanol injection therapy," Journal of Nanoparticle Research, vol. 15, Article ID 2131, 2013.

[53] E. Hara, A. Makino, K. Kurihara, F. Yamamoto, E. Ozeki, and S. Kimura, "Pharmacokinetic change of nanoparticulate formulation "Lactosome" on multiple administrations," International Immunopharmacology, vol. 14, no. 3, pp. 261-266, 2012.

[54] T. Ishida and H. Kiwada, "Accelerated blood clearance (ABC) phenomenon upon repeated injection of PEGylated liposomes," International Journal of Pharmaceutics, vol. 354, no. 1-2, pp. 5662, 2008.

[55] A. S. Abu Lila, H. Kiwada, and T. Ishida, "The accelerated blood clearance $(\mathrm{ABC})$ phenomenon: clinical challenge and approaches to manage," Journal of Controlled Release, vol. 172, no. 1, pp. 38-47, 2013.

[56] E. Hara, A. Makino, K. Kurihara et al., "Evasion from accelerated blood clearance of nanocarrier named as "lactosome" induced by excessive administration of Lactosome," Biochimica et Biophysica Acta-General Subjects, vol. 1830, no. 8, pp. 40464052, 2013.

[57] E. Hara, M. Ueda, A. Makino, I. Hara, E. Ozeki, and S. Kimura, "Factors influences in vivo disposition of polymeric micelles on multiple administrations," ACS Medicinal Chemistry Letters, vol. 5, no. 8, pp. 873-877, 2014.

[58] P.-L. Lu, Y.-C. Chen, T.-W. Ou et al., "Multifunctional hollow nanoparticles based on graft-diblock copolymers for doxorubicin delivery," Biomaterials, vol. 32, no. 8, pp. 2213-2221, 2011.

[59] M. G. Wacker, "Nanotherapeutics-product development along the nanomaterial discussion," Journal of Pharmaceutical Sciences, vol. 103, no. 3, pp. 777-784, 2014. 


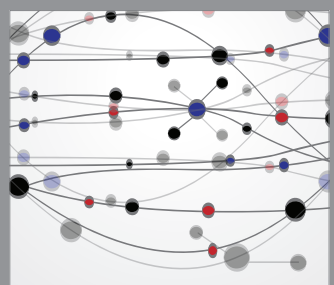

The Scientific World Journal
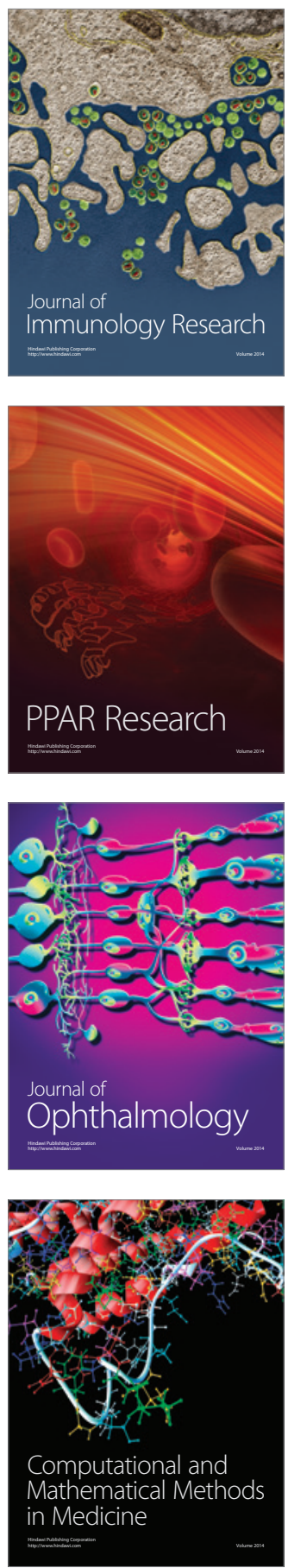

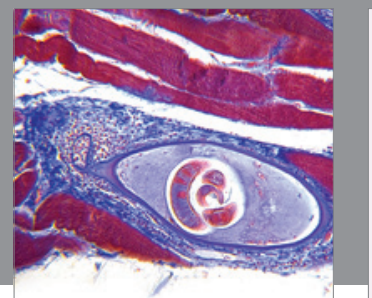

Gastroenterology

Research and Practice
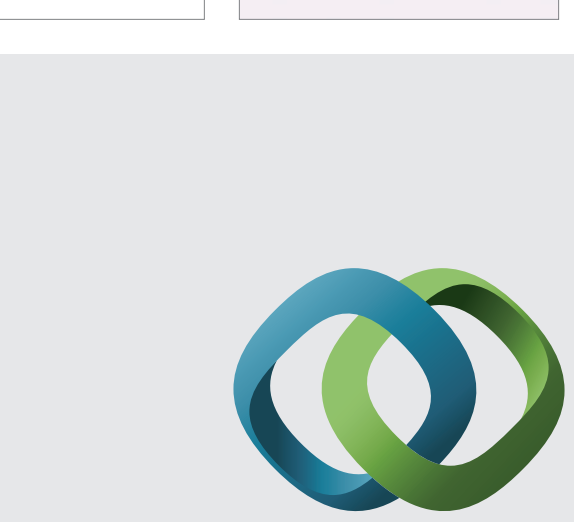

\section{Hindawi}

Submit your manuscripts at

http://www.hindawi.com
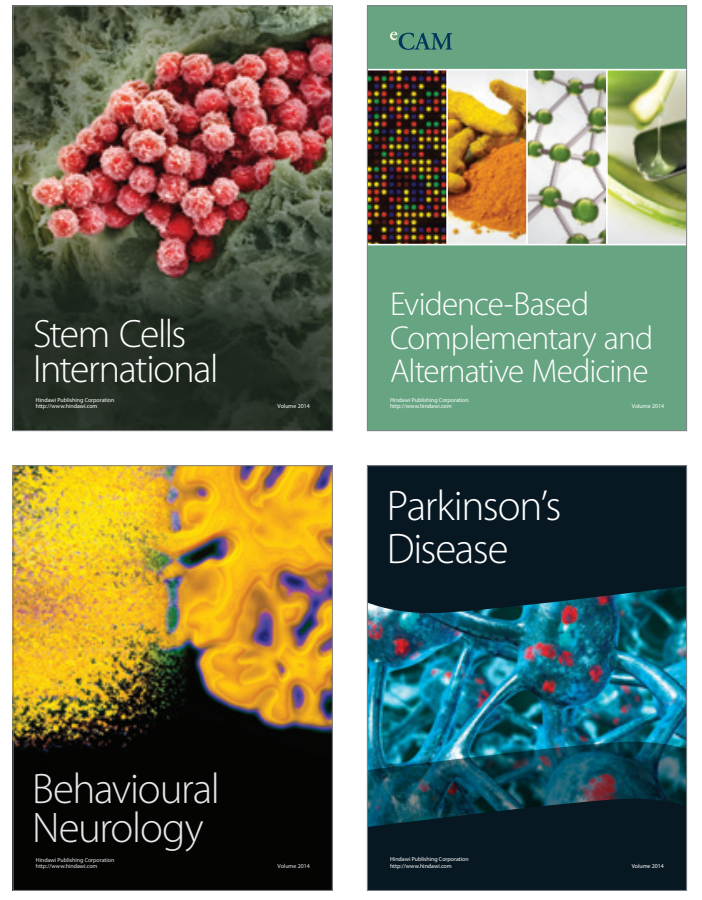
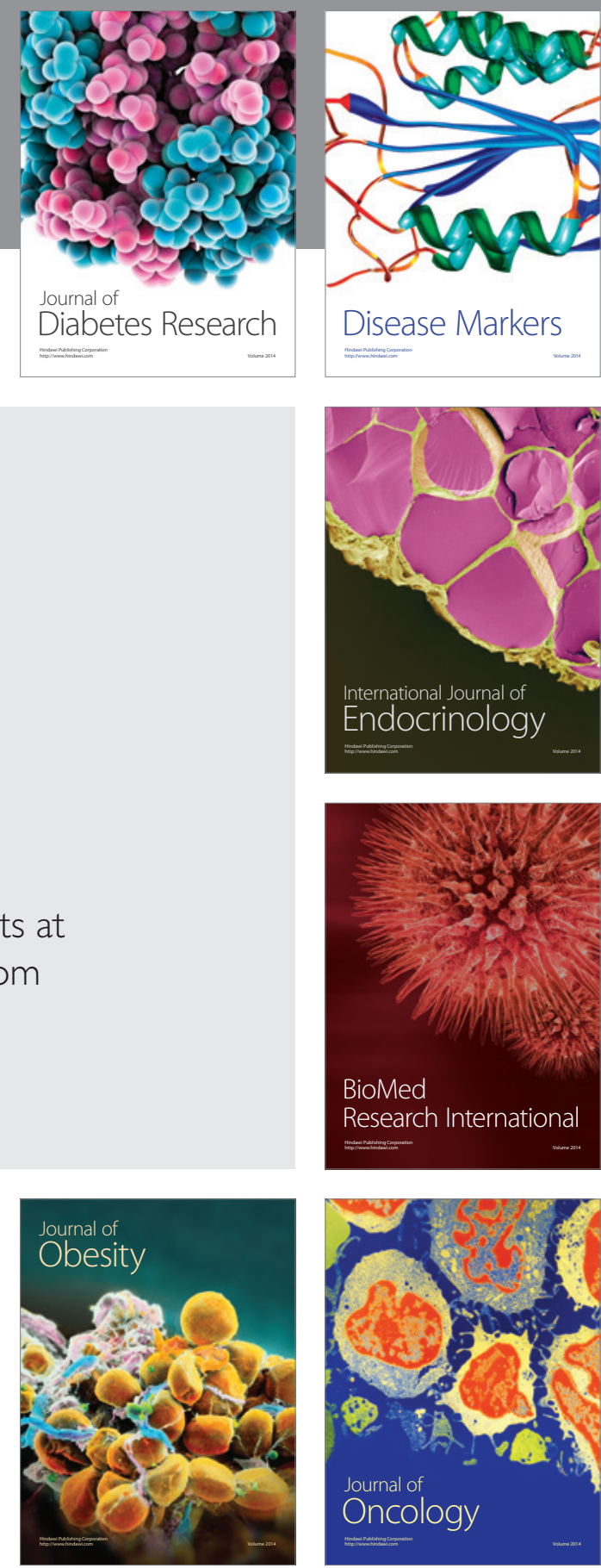

Disease Markers
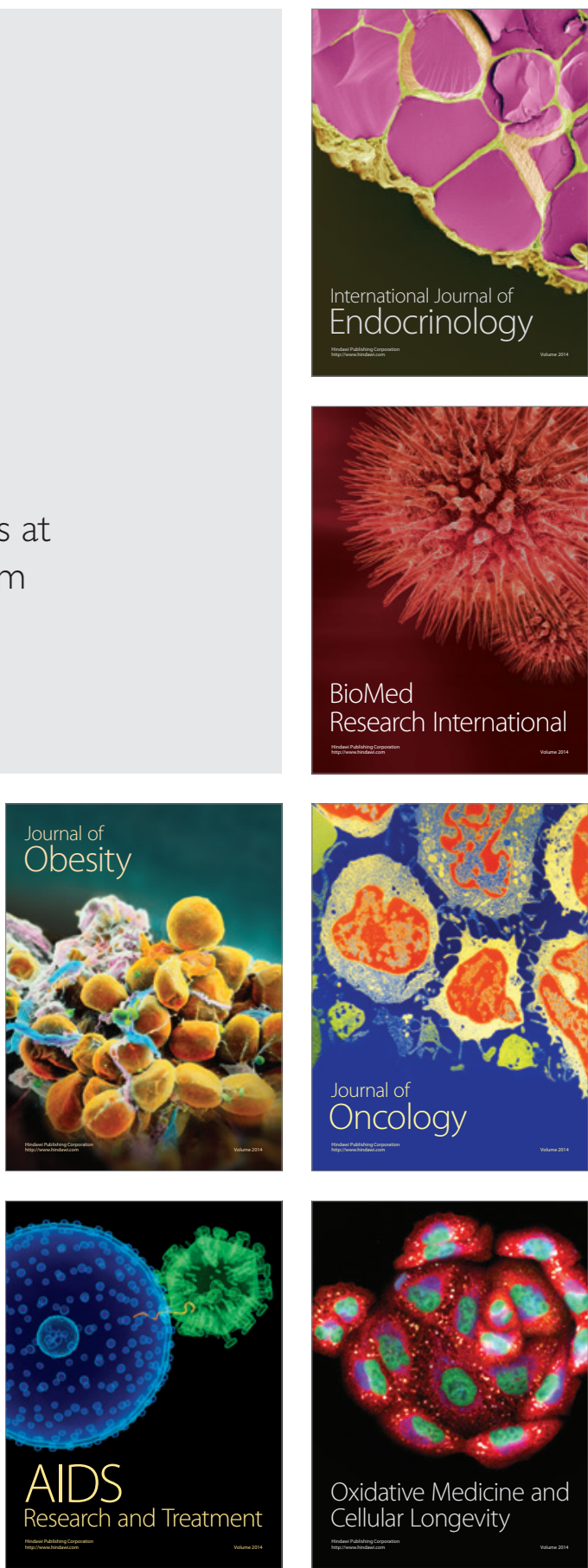